\title{
Novel flavours paired with glutamate condition increased intake in older adults in the absence of changes in liking
}

Article

Accepted Version

Dermiki, M., Prescott, J., Sargent, L. J., Willway, J., Gosney, M. A. and Methven, L. (2015) Novel flavours paired with glutamate condition increased intake in older adults in the absence of changes in liking. Appetite, 90. pp. 108-113. ISSN 0195-6663 doi: https://doi.org/10.1016/j.appet.2015.03.002 Available at https://centaur.reading.ac.uk/39482/

It is advisable to refer to the publisher's version if you intend to cite from the work. See Guidance on citing.

To link to this article DOI: http://dx.doi.org/10.1016/j.appet.2015.03.002

Publisher: Elsevier

All outputs in CentAUR are protected by Intellectual Property Rights law, including copyright law. Copyright and IPR is retained by the creators or other copyright holders. Terms and conditions for use of this material are defined in the End User Agreement.

www.reading.ac.uk/centaur 
Central Archive at the University of Reading

Reading's research outputs online 
1 Novel flavours paired with glutamate condition increased intake in older adults in the absence of changes in liking

Maria Dermiki ${ }^{a}$, John Prescott ${ }^{b}$, Laura J Sargent ${ }^{a}$, Joanne Willway ${ }^{a}$, Margot A.Gosney ${ }^{c}$ and Lisa Methven ${ }^{a, *}$

${ }^{a}$ Department of Food and Nutritional Sciences, University of Reading, Whiteknights, Reading, RG6 6AP, UK

${ }^{\mathrm{b}}$ TasteMatters Research \& Consulting, Sydney, Australia [Prescott@taste-matters.org] ${ }^{\mathrm{C} C l i n i c a l}$ Health Sciences, University of Reading, London Road, Reading, RG1 5AQ, UK *Correspondence to: Dr Lisa Methven, Department of Food and Nutritional Sciences, University of Reading, Whiteknights, Reading, RG6 6AP, UK, email: I.methven@reading.ac.uk

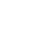

\begin{abstract}
Previous research on the repeat exposure to a novel flavour combined with monosodium glutamate (MSG) has shown an increase in liking and consumption for the particular flavour. The aim of the current work was to investigate whether this could also be observed in the case of older people, since they are most affected by undernutrition in the developed world and ways to increase consumption of food are of significant importance for this particular age group. For this study, 40 older adults (age 65-88) repeatedly consumed potato soup with two novel flavours (lemongrass and cumin) which were either with or without a high level of MSG $(5 \% \mathrm{w} / \mathrm{w})$. A randomized single blind within-subject design was implemented, where each participant was exposed to both soup flavours three times over 6 days, with one of the soup flavours containing MSG. After three repeat exposures, consumption increased significantly for the soups where the flavours had contained MSG during the repeated exposure (mean weight consumed increased from 123 to $164 \mathrm{~g}, \mathrm{p}=0.017$ ), implying that glutamate conditioned for increased wanting and consumption, despite the fact that the liking for the soup had not increased.
\end{abstract}

\title{
Highlights
}

- Glutamate can condition increased food consumption in older adults

- Older adults increased consumption of novel flavoured soups paired with glutamate

- Older adults did not increase liking of novel flavoured soups paired with glutamate

\section{Keywords}

Conditioned liking, conditioned intake, wanting, consumption, glutamate 


\section{Introduction}

While repeated exposure alone can produce increased liking for food/beverage flavours (Methven, Langreney, \& Prescott, 2012), it is thought that most flavour or food preferences are formed through associative learning in which the flavour is paired with a liked taste such as sweetness (flavour-flavour learning, FFL; (Yeomans, Mobini, Elliman, Walker, \& Stevenson, 2006) or with ingested nutrients (flavour-consequence learning, $F C L$ ) including carbohydrates (Yeomans, Leitch, Gould, \& Mobini, 2008) and fat (Kern, McPhee, Fisher, Johnson, \& Birch, 1993). Nutrient pairing has been shown to lead to produces reliably strong increases in liking for a paired flavour in some studies (Brunstrom \& Mitchell, 2007; Kern, et al., 1993; Yeomans, Leitch, et al., 2008) but not all (Remy, Issanchou, Chabanet, \& Nicklaus, 2013). Typically the effect is only successful under conditions in which the nutrient is valued. Hence, learning is strongly dependent on hunger state, an observation which emphasizes the key role of the metabolic consequences of the nutrients in facilitating the increased flavour liking (Mobini, Chambers, \& Yeomans, 2007). It is however noted that where the taste is generally associated with nutritive value, for example sweetness and sugar, FFL can still result from low-nutritive value (low calorie) sweetness pairings (Privitera, Mulcahey, \& Orlowski, 2012).

FCL has also been demonstrated with glutamate in the form of its sodium salt, monosodium glutamate (Prescott, 2004; Yeomans, Gould, Mobini, \& Prescott, 2008). The metabolic underpinnings of this process are less clear than they are for the similar effects produced by sugar or fat, both sources of energy. However, glutamate is an amino acid and the human body requires sources of amino acids and protein, so the fact that glutamate increases savoury taste and food pleasantness may increase motivation to consume foods as a response to ensure adequate protein intake (Murphy, 1987). There are also data suggesting an important metabolic role for glutamate as an intestinal energy source (Reeds, Burrin, Stoll, \& Jahoor, 2000).

Motivation to consume sufficient protein is the basis of the "protein leverage hypothesis" whereby it is proposed that humans have an appetite for protein which within low protein diets can lead to excessive energy intake. In a recent study by Gosby, et al. (2011), lowering protein in the diet (from $15 \%$ to $10 \%$ ) led to higher total energy intake which was 
predominantly consumed through savoury-flavoured foods. This supports the theory that savoury taste signals for protein.

Repeatedly pairing a novel soup flavour with ingested glutamate was found to produce a substantially stronger preference than either simple repeated exposure to the soup flavour or to the soup flavour paired with glutamate but ingested in only nominal amounts, a condition equivalent to FFL (Prescott, 2004). In a subsequent study (Yeomans, Gould, et al., 2008), conditioned flavour liking from ingested glutamate added to soups was also observed. In addition, this later study also examined the impact of glutamate-conditioned flavours on post-conditioning intake and hunger. Relative to a control condition in which the soup did not contain added MSG, pairing with MSG produced a significant increase in ad-libitum soup intake following conditioning. As well, tasting the soup whose flavour had been paired with MSG increased ratings of hunger, again an effect not evident in the control condition.

In contrast to measures of liking, hunger might be considered a motivational consequence of ingested MSG in such conditioning paradigms. Distinctions between affective (liking) and motivational (wanting) aspects of consumption have been highlighted by Berridge (Berridge, 1996, 2009), initially as an explanatory principle underlying drug addictions. The two psychological processes of liking and wanting operate at explicit (deliberative) and implicit (automatic) levels (Finlayson \& Dalton, 2012) and there have been a number of studies that focused on developing methodologies in order to understand the extent to which this distinction applies to food consumption (Finlayson, King, \& Blundell, 2006, 2007) and the importance of the distinction in providing explanations for food-related issues such as obesity and binge-eating (Finlayson, Arlotti, Dalton, King, \& Blundell, 2011; Finlayson, King, \& Blundell, 2008; Griffioen-Roose, Finlayson, Mars, Blundell, \& de Graaf, 2010; Temple, et al., 2009).

However, whereas obesity is of concern to the main stream western populations, the incidence of under-nutrition is widespread among older people (Age Concern, 2006) and 
factors that may increase intake or hunger are consequently of practical interest. One of the physiological factors that results in reduced food intake is the natural decline of taste and olfaction due to ageing (Kenway, et al., 2004; Methven, Allen, Withers, \& Gosney, 2012; Schiffman \& Warwick, 1993), or due to diseases and medication (Nolan, 2001; Schiffman, 2007; Schiffman, et al., 2000; Winkler, Garg, Mekayarajjananonth, Bakaeen, \& Khan, 1999), which can lead to a reduced appreciation and interest in food. Moreover, perhaps as a consequence of such sensory deficits, it is not at all clear that either FFL or FCL operate as effectively in elderly populations as they do in the younger age groups that have been studied to date.

Here we report the results of a study in which the pairing of MSG with a novel soup flavour produced conditioned increases in soup consumption in the absence of conditioned liking. In this particular study, we investigated how repeated exposure to MSG could influence both liking for paired soup flavour as well as willingness to consume the soup in older healthy adults.

\section{Materials and Methods}

\section{Design}

This single blind study used a within subjects design to measure the effect of MSGenhanced soup on liking and consumption by older adults, following repeat exposure. The participants were asked to attend a pre-training conditioning session (session 1, S1) and a post-training conditioning session (session 8, 58) at a central location (the university). At the pre-training conditioning session they were required to take home 6 cans of soup for their consumption over the week. Two different flavours of soup, cumin and lemongrass, were used account for mere exposure effects of increased liking to the flavour regardless of the addition of MSG. Each flavour was consumed on alternate days throughout the week (Table 1). The order in which the flavours were consumed was balanced across participants. For each group one soup contained added MSG, the other did not. In preand post- training conditioning sessions, the soups tasted and consumed did not contain added MSG. 


\section{Participants}

130 Forty volunteers (10 men, 30 women; 65 - 88 years old, mean age: $73.7 \pm 5.5$ years) were recruited from a database of healthy older volunteers whom had previously stated an interest in taking part in research studies. Each participant received a participant information sheet and on agreeing to take part in the study they completed a consent form. A screening questionnaire determined their eligibility to take part in the study; exclusion criteria were the existence of relevant food allergies or intolerances, taking medications known to affect appetite or taste and age under 65 years. The volunteers selfreported height and weight, from which their BMI was calculated. The majority of participants were in the healthy weight BMI category, the mean BMI was $23.7 \mathrm{kgm}^{-2}$, the median was $23.1 \mathrm{kgm}^{-2}$, and the overall range was 18.6 to $31.9 \mathrm{kgm}^{-2}$. No volunteers were reportedly underweight $\left(<18.5 \mathrm{kgm}^{-2}\right.$ ), eight were in the overweight category (25 to 29.9 $\mathrm{kgm}^{-2}$ ) and two in the obese category (30 to $39.9 \mathrm{kgm}^{2}$ ).

Participants were allocated randomly to one of two groups (ASSG ${ }^{+}$and MSG Group 1 or Group 2) which determined which of the soups to be taken home contained added MSG and which did not. Each group was then further segmented in terms of which flavour soup they would consume on the pre- and post-conditioningtraining sessions (the one exposed with MSG or the one exposed without MSG). The two groups did not differ in terms of gender (both groups had 5 men and 15 women) or differ significantly in terms of age ( $\mathrm{MSG}^{+}: 72.8 \pm 4.9$ years; $\mathrm{MSG}^{-}: 74.6 \pm 6.1$ years, $\mathrm{p}=0.298$ ). One participant failed to attend post-trainingconditioning, so her results were excluded from the study. The project was given approval to proceed by the University of Reading Research Ethics Committee (study number 11/41).

\section{Samples}

155 A potato soup was prepared as a base and two different concentrated flavour 
preparations, lemongrass and cumin (Treatt, Bury St Edmunds, UK) were added to create the two different soup flavours. The soups were then processed in a canning retort at $121^{\circ} \mathrm{C}$ in either $400 \mathrm{ml}$ or $120 \mathrm{ml}$ cans, the larger size for the consumption tests and the smaller sizes for the repeat exposure tastings. The particular flavours chosen were considered novel for this age group and were used in order to avoid any effects of familiarity on liking and consumption of the soups. All soups were prepared in the pilot plant in University of Reading, following good manufacturing practices (GMP) and Hazard Analysis Critical Control Points (HACCP). To half of the soup samples provided during the training conditioning sessions (see below) $5 \%$ MSG w/w was added.

\section{Procedure}

Pre-training-conditioning session (session 1): Volunteers tasted both of the two flavours of soup and rated their liking for them on a standard 9-point hedonic category scale $(1=$ dislike extremely and $9=$ like extremely). They were also asked to rank their prestate which of the two samples they preferred. Soups were presented in a balanced order and participants were asked to rinse their palate with water between samples. Additional questions were asked on familiarity of each soup flavour as well as questions on appetite and mood. These were rated using unstructured line scales (results scaled 0-100) with anchors at both ends (Table 1). They were then presented one soup for consumption. Each volunteer was asked to eat as much soup as they wanted; they were provided with both a bowl of soup $(250 \mathrm{ml})$ alongside an additional thermos flask of soup (total amount of soup was $400 \mathrm{ml}$ ). Consumption weight was calculated. Then participants were asked further questions on appetite (Table 1ㅁQ Q7-8).

Fraining Conditioning sessions (Sessions 2 - 7): The volunteers took home six cans of soup $(120 \mathrm{ml})$, three of each flavour, to consume on alternate days over the 6 days with one flavour containing added MSG. Instructions were given to each volunteer on how to reheat the soup and they were asked to consume one can of soup $(120 \mathrm{ml})$ at their normal lunch time each day, recording the time they ate and any other comments on a chart provided. 
Post-training-conditioning (Session 8): During the post-trainingconditioning session, held at the central location (University), the volunteers repeated the liking and preference test and answered the same questions on familiarity, appetite and mood as in the pretrainingconditioning, and in the same order (session 1). They were also presented with the same soup for consumption as they had been in session 1. Moreover, they were asked to eat the same breakfast at the same time on both the pre- and post-conditioningtraining days and not to consume anything apart from water between breakfast and lunchthe midday session. Both pre- and post- conditioningtraining sessions were commenced at midday with participants seated in isolated sensory booths.

\section{Statistical analysis}

Analysis of the data was conducted with XLSTAT (Addinsoft, version 2011.4.01).

Correlation tests were done using Pearson correlation matrix. Comparison of measures between flavours and sessions were carried out using $t$ tests. The effect of soup flavour, exposure to MSG and gender on the difference in consumption, liking and familiarity preand post raining conditioning were carried out using analysis of variance. Difftest (Statbasics, version 2.00) was used to determine the significance of the preference results. For all tests, significance was established at $p<0.05$.

\section{Results}

Liking

Liking ratings for the soups were low with mean liking ratings across both flavours being 5.7 and 5.4 out of 9 at sessions 1 and 8 respectively. The liking of the soups was significantly affected by the flavour $(F(1,148)=3.90, p=0.05)$ with the lemongrass scoring lower than the cumin flavour in both S1 (mean rating 5.3 compared to 6.1) and S8 (5.3 compared to 5.6). However, liking was not significantly affected by the session (pre- to post conditioningtraining $)(F(1,148)=0.49, p=0.48)$, the exposure group $(F(1,148)=1.05, p=0.31)$ 
or gender $(F(1,148)=0.21, p=0.65)$. There were no significant interactions between any of the treatment effects.

The difference in liking between the pre- and post conditioningtraining was not significantly affected by the soup flavour $(F(1,73)=0.95, p=0.33)$, whether that flavour had been previously paired with MSG $(F(1,73)=0.01, p=0.93)$, or gender $(F(1,73)=0.60, p=0.44)$, and there was no significant interaction between flavour and exposure group $(F(1,73)=0.90, p=0.35)$ (Figure 1). There was a significant correlation between familiarity and liking, across all soup flavours and sessions $(r=0.25, p=0.002)$.

The scores for "would you choose this soup" were below the mid-point on a 100 point scale (mean values of 37.8 and 35.6 across both soup flavours at S1 and S8, respectively). There were no significant effects of flavour $(F(1,147)=2.59, p=0.11)$, session $(F(1,147=0.23$, $p=0.63)$, exposure group $(F(1,147=1.14, p=0.29)$ or gender $(F(1,147=0.09, p=0.76)$ on the readiness to choose the soup, and no significant interactions between these factors.

\section{FIGURE 1 ABOUT HERE}

\section{Preference}

In neither S1 nor S8, was $t$ There was no significantany difference in the number of subjects who preferred the cumin one soup flavoured soup over another the lemongrass flavoured soup in either $\mathrm{S} 1$ or $\mathrm{S} 8$ ( $\mathrm{n}=22$ cumin, $\mathrm{n}=17$ lemongrass; at both sessions).

\section{Familiarity}

Familiarity was rated low for both soups in S1 (mean values out of 100: cumin 30.3, lemongrass 20.6), confirming initial judgments of flavour novelty. Significant effects on changes in familiarity between the pre- and post- exposure sessions were seen as a function of flavour $(F(1,71)=3.89, p=0.025)$ and gender $(F(1,71)=3.89, p=0.05)$, but not exposure group $(F(1,71)=0.15, p=0.70)$. Familiarity increased significantly from $S 1$ to $S 8$ for the lemongrass flavour $(t(76)=3.44, p=0.001)$ but not for the cumin flavour $(t(74)=1.17$, 
$p=0.25)$. The apparent difference in change in familiarity as a function of exposure with MSG shown in Figure 2 was not significant (interaction between flavour and exposure group: $F(1,71)=1.27, p=0.26)$, whereas the familiarity of the lemongrass flavour increased between the sessions whether exposed with MSG or not.

\section{FIGURE 2 ABOUT HERE}

\section{Appetite and Mood}

The participants pre-lunch hunger, desire to eat and mood ratings did not change significantly between sessions (Figure 3$)(t(74)=0.93, p=0.35 ; t(74)=0.63, p=0.53$; $t(74)=0.05, p=0.96$ respectively) . The mean hunger and desire to eat ratings were midscale implying the participants were moderately hungry at the time of the tests, and the mean mood rating was high implying the participants were in a pleasant mood.

\section{Although post consumption the overall mean satiety ratings were not higher in S8} compared to $\mathrm{S} 1 \mathrm{t}(\mathrm{t}(\mathrm{6})=1.29, \mathrm{p}=0.2)$, the mean values were lower than the mid-point of the scale (S1: 43.2; S8: 35.2), implying that the participants had not eaten to fullness. However, when asked if they could eat any more of the soup the values were also low on the scale, with no significant differences between S1 and S8 (21.5 compared to $30.2 ; t(75)=1.45$, $\mathrm{p}=0.15)$.

There were no significant effects of gender $(F(1,70)=0.02, p=0.89)$, soup flavour $(F(1,70)=0.09, p=0.77)$, exposure group (whether the soup flavour had been exposed to MSG during the conditioningtraining period) $(F(1,70)=0.04, p=0.85)$, nor session (pre- or post conditioningtraining) $(F(1,70)=1.63, p=0.21)$ on post-consumption satiety ratings and no significant interactions of any of the treatment effects. Similarly, there were no significant effects of gender $(F(1,69)=0.03, p=0.87)$, soup flavour $(F(1,69)=0.01, p=0.92)$, 
exposure group $(F(1,69)=2.08, p=0.15)$, nor session $(F(1,69)=2.11, p=0.15)$ on the "could you eat more" rating and no significant interactions of any of the treatment effects.

\section{Compliance and Comments}

During the 6 day exposure period the participants were asked to note whether they ate the soups and to provide free-text comments. Of the 39 participants, $32(82 \%)$ ate all of the soup provided on all days, 1 person forgot to eat the soup on one day, 5 participants ate only a quarter or half of the portion each day and one participant did not provide compliance information. Twenty-six participants (67\%) commented that the soups were salty and of these comments $16(41 \%)$ were specific to the soups containing MSG.

\section{Consumption}

Following the liking ratings, and prior to the consumption test, participants were asked to rate "how much could you eat of this soup now?". These ratings were below the mid-point on a 100 point scale (means: 40.5 and 38.1 , across both soup flavours at S1 and S8). There were no significant effects of flavour $(F(1,146)=2.29, p=0.13)$, session $(F(1,146=0.31$, $p=0.58)$, exposure group $(F(1,146=1.72, p=0.19)$ or gender $(F(1,146=0.48, p=0.49)$ on the expected consumption of the soup, and no significant interactions between these factors.

However, pairing with MSG over the conditioning sessions did lead to a significant effect on intake at the post-conditioning session. There was an increase in consumption of the soups between $\mathrm{S} 1$ and S8, but only in the condition where the soup had been previously paired with MSG $(F(1,34)=6.34, p=0.017)($ Figure 4). The mean consumption of soups which had been paired with MSG increased from $123 \mathrm{~g}$ at the pre-conditioning session to $164 \mathrm{~g}$ at the post conditioning session (standard error 24), whereas the consumption of soups not paired with MSG remained virtually constant (130 g and $121 \mathrm{~g}$ respectively).

There was a positive correlation between soup consumption across both sessions with liking $(r=0.61, p<0.0001)$ and familiarity $(r=0.29, p=0.009)$. However, there was no 
correlation between consumption and rated hunger $(r=0.13, p=0.24)$. There were no changes in consumption associated with soup flavour $(F(1,34)=0.49, p=0.49)$ or gender $(F(1,34)=0.69, p=0.41)$.

\section{Discussion}

The major finding from this study is that repeat exposure to novel-flavoured soups with MSG increased consumption by older people after three at-home exposures. This finding is consistent with previous research that MSG can condition both appetite and consumption (Yeomans, Gould, et al., 2008). However, unexpectedly, the current data failed to show an increase in conditioned liking for the soup flavours. The failure to show an increase in hedonic ratings was consistent with the relatively low scores both pre- and postconditioning for the question "would you choose this soup". The lack of increased liking following conditioning, contrary to expectations, is unlikely to be a function of the soup flavours themselves, novel though they were. Previous research has used highly novel, indeed somewhat unpalatable, flavours while still showing increased liking over repeat exposures, even without consumption (Prescott, 2004).

A more likely cause is the soups' salt content, an important determinant of the flavour acceptability of foods. In particular, appropriate salt levels are dependent on the context of the particular food (Sullivan \& Birch, 1990). The average sodium level in UK soups is 224 $\mathrm{mg} / 100 \mathrm{ml}$ (data taken from eight UK supermarket canned soups), which is comparable to the soup with no MSG used in this study $(255 \mathrm{mg} / 100 \mathrm{ml})$. However, we subsequently determined that the sodium level of the soup with 5\% MSG was $983 \mathrm{mg}$ per $100 \mathrm{ml}$, so the $120 \mathrm{ml}$ samples that were consumed provided $1180 \mathrm{mg}$ sodium. We suggest, therefore, that the soups are highly likely to have been unpalatably salty. Comments received from many of the participants to the effect that some of the soups were too salty support this interpretation. Of course, the MSG- soups also failed to show changes in liking, but this may have reflected an entirely different mechanism, for example, insufficient exposure to 
such flavour novelty.

Thus, although conditioned increases in consumption are most often accompanied by increases in liking (Yeomans, Gould, et al., 2008) these two processes were affected differently by the added MSG in this study. Effectively, this implies that FFL, the high $\mathrm{Na}$ sodium paired with the soup flavours, was acting to offset any conditioned liking that might have arisen as a result of pairing MSG with the flavour. In contrast, the ingested MSG paired with the flavour facilitated FNL, which provided the basis for conditioned increases in post-conditioning intake. In effect, we report here a serendipitous finding of conditioned intake in the absence of conditioned liking. As to whether this dissociation is a function of other aspects of the design apart from the high Na-sodium content of the soups is not clear. Multiple exposures can in fact increase liking for a flavour that is initially unpalatable due to low Na-sodium content (Methven, Langreney, et al., 2012), so the possibility exists that further exposure in this case may also have led to increased liking.

One interpretation of this dissociation is that it reflects separate processes inherent in the liking/wanting distinction. There are substantial difficulties in disentangling liking and wanting as reasons for intake, as both factors are likely to coincide most often (Havermans, 2011). Moreover, the learning processes behind each are likely to coincide. Thus, the results from Yeomans, Gould, et al. (2008) showed that pairing a flavour with an ingested nutrient such as glutamate under conditions of hunger produced both increased liking for the flavour and increased consumption of it. But conceptually, these two processes can be distinguished. As an illustration, a simple case in which they are dissociated might be where we would be willing to eat a food that was otherwise highly unpalatable if we were sufficiently hungry.

Of course, food intake can occur for a variety of reasons not associated with motivational states, including such cases as mindless eating (Braude \& Stevenson, 2014). However, in the present study the increased intake was specifically associated with the addition of MSG to the soup. Moreover, other recent studies have provided evidence of liking/wanting 
dissociation. Repeat exposure has been shown to lead to increased consumption of snack foods without subsequent increase of liking in the case of obese and non-obese women (Temple, et al., 2009). In the study conducted by Finlayson, King and Blundell (2007) they attempted to develop a methodology in order to dissociate wanting from liking and they also found that more differences in liking were observed when the participants were hungry than when satiated. These studies, plus the data from the present study, strongly indicate that, since motivation and liking can be dissociated, at least potentially, it is crucial to measure both phenomena.

Lastly, this research provides evidence that repeat exposure to novel foods with glutamate could result in increased appetite and consumption in older people. This is important for two reasons. Firstly, in these populations, under-nutrition is of particular concern, so strategies in increase food consumption are needed. Secondly, almost all studies on FFL and FNL have been conducted on young adults or children, and so there has been a need to establish that the same processes of learning occur in elderly populations, who may differ not only in their perceptual abilities but also particularly in their responses to novel foods (Meiselman, King, \& Gillette, 2010). A previous study of a frail elderly population (Essed, van Staveren, Kok, \& de Graaf, 2007) over a period of 16 weeks found no effect on rated pleasantness and measured consumption when $0.3 \%$ MSG was added to the animal protein part of a cooked meal. It may be that higher levels of MSG are required to trigger a change in consumption, perhaps due to post-ingestive effects. The concentration of MSG used in the present study was substantially higher than in previous studies, therefore, it remains to be determined whether lower levels (0.5 to $1 \%)$ are sufficient to trigger post-ingestive effects and increase food consumption.

In addition, while the volunteers participating in the present study were all older people, they were all healthy and none were reportedly underweight. It would be of benefit to further study frailer older adults at risk of under nutrition. For those in elderly care homes or elderly care wards in hospital, malnutrition is estimated to be $60 \%$ in those over 65 (Age Concern, 2006). Since the glutamate rather than the sodium was responsible for the increase wanting, the use of other sources of glutamate apart from MSG may be preferable 
393 as a supplement to foods in such situations. The results may be generalizable to the use of 394 natural food sources of glutamate and 5' ribonucleotides (Dermiki, et al., 2013; Dermiki, et 395 al., 2014). Thus, our studies have shown that a combinations of natural ingredients can 396 lead to higher umami taste in savoury meals than can be achieved by the addition of MSG 397 alone (Dermiki, et al., 2013). Future work should focus on the longevity of this increase in 398 appetite and consumption after MSG has been removed from the food. If the increase is 399 completely due to FCL then constant addition of MSG may be required in food, since there 400 is some evidence that such learning can extinguish (O'Sullivan, Alexander, Ferriday, \& 401 Brunstrom, 2010). However if FFL is important, especially in novel foods, then only a small 402 number of exposures to MSG may be required, since such learning is thought to be 403 permanent (Baeyens, Crombez, Bergh, \& Eelen, 1988).

\section{Acknowledgments}

406 The authors would like to thank all volunteers who took part in the study. 


\section{References}

Age Concern. (2006). Hungry to be Heard: The Scandal of Malnourished Older People in Hospital. London: Age Concern England.

Baeyens, F., Crombez, G., Bergh, O. v. d., \& Eelen, P. (1988). Once in contact always in contact: Evaluative conditioning is resistant to extinction. Advances in Behavioural Research and Therapy, 10, 179-199.

Berridge, K. C. (1996). Food reward: Brain substrates of wanting and liking. Neuroscience and Biobehavioral Reviews, 20, 1-25.

Berridge, K. C. (2009). 'Liking' and 'wanting' food rewards: Brain substrates and roles in eating disorders. Physiology \& Behavior, 97, 537-550.

Braude, L., \& Stevenson, R. J. (2014). Watching television while eating increases energy intake. Examining the mechanisms in female participants. Appetite, 76C, 9-16.

Brunstrom, J. M., \& Mitchell, G. L. (2007). Flavor-nutrient learning in restrained and unrestrained eaters. Physiology \& Behavior, 90, 133-141.

Dermiki, M., Mounayar, R., Suwankanit, C., Scott, J., Kennedy, O. B., Mottram, D. S., Gosney, M. A., Blumenthal, H., \& Methven, L. (2013). Maximising umami taste in meat using natural ingredients: effects on chemistry, sensory perception and hedonic liking in young and old consumers. Journal of the Science of Food and Agriculture, 93, 33123321.

Dermiki, M., Willway, J., Sargent, L. J., Kidman, J. A., Anderson, C., Kennedy, O. B., Gosney, M. A., \& Methven, L. (2014). Preference and consumption of a taste enhanced meat meal by older hospital patients: A pilot study. Nutrition and Aging, 2, 69-75.

Essed, N. H., van Staveren, W. A., Kok, F. J., \& de Graaf, C. (2007). No effect of 16 weeks flavor enhancement on dietary intake and nutritional status of nursing home elderly. Appetite, 48, 29-36.

Finlayson, G., Arlotti, A., Dalton, M., King, N., \& Blundell, J. E. (2011). Implicit wanting and explicit liking are markers for trait binge eating. A susceptible phenotype for overeating. Appetite, 57, 722-728.

Finlayson, G., \& Dalton, M. (2012). Current progress in the assessment of 'liking' vs. 'wanting' food in human appetite. Comment on '"You Say it's Liking, I Say it's Wanting ... ". On the difficulty of disentangling food reward in man'. Appetite, 58, 373-378.

Finlayson, G., King, N., \& Blundell, J. E. (2006). Separation of 'liking' and 'wanting' for foods in humans: Confirmation using a refined novel experimental procedure. Appetite, 47, 263.

Finlayson, G., King, N., \& Blundell, J. E. (2007). Is it possible to dissociate 'liking' and 'wanting' for foods in humans? A novel experimental procedure. Physiology and Behavior, 90, 36-42.

Finlayson, G., King, N., \& Blundell, J. E. (2008). The role of implicit wanting in relation to explicit liking and wanting for food: Implications for appetite control. Appetite, 50, 120-127.

Gosby, A. K., Conigrave, A. D., Lau, N. S., Iglesias, M. A., Hall, R. M., Jebb, S. A., Brand-Miller, J., Caterson, I. D., Raubenheimer, D., \& Simpson, S. J. (2011). Testing protein leverage in lean humans: a randomised controlled experimental study. Plos One, 6, e25929 [25911pp.]-e25929 [25911pp.].

Griffioen-Roose, S., Finlayson, G., Mars, M., Blundell, J. E., \& de Graaf, C. (2010). Measuring food reward and the transfer effect of sensory specific satiety. Appetite, 55, 648655.

Havermans, R. C. (2011). "You Say it's Liking, I Say it's Wanting ... ". On the difficulty of disentangling food reward in man. Appetite, 57, 286-294. 
Kenway, N., Jean, W., Mandy, K., Mandy, S., Angela, W., Raymond, L., Anthony, C., \& Henry, C. J. K. (2004). Effect of age and disease on taste perception. Journal of pain and symptom management, 28, 28-34.

Kern, D. L., McPhee, L., Fisher, J., Johnson, S., \& Birch, L. L. (1993). The postingestive consequencies of fat condition preferences for flavors associated with high dietaryfat. Physiology \& Behavior, 54, 71-76.

Meiselman, H. L., King, S. C., \& Gillette, M. (2010). The demographics of neophobia in a large commercial US sample. Food Qual Pref, 21, 893-897.

Methven, L., Allen, V. J., Withers, C. A., \& Gosney, M. A. (2012). Ageing and taste. Proceedings of the Nutrition Society, 71, 556-565.

Methven, L., Langreney, E., \& Prescott, J. (2012). Changes in liking for a no added salt soup as a function of exposure. Food Quality and Preference, 26, 135-140.

Mobini, S., Chambers, L. C., \& Yeomans, M. R. (2007). Effects of hunger state on flavour pleasantness conditioning at home: Flavour-nutrient learning vs. flavour-flavour learning. Appetite, 48, 20-28.

Murphy, C. (1987). Flavor preference for monosodium glutamate and casein hydrolysate in young and elderly persons. In Y. Kawamura \& M. R. Kare (Eds.), Umami: A Basic Taste (pp. 139-151). New York: Marcel Dekker, Inc.

Nolan, N. M. (2001). Medication-Induced Taste Disturbances. Nutrition in Clinical Care, 4, 4352.

O'Sullivan, H. L., Alexander, E., Ferriday, D., \& Brunstrom, J. M. (2010). Effects of repeated exposure on liking for a reduced-energy-dense food. American Journal of Clinical Nutrition, 91, 1584-1589.

Prescott, J. (2004). Effects of added glutamate on liking for novel food flavors. Appetite, 42, 143-150.

Privitera, G. J., Mulcahey, C. P., \& Orlowski, C. M. (2012). Human sensory preconditioning in a flavor preference paradigm. Appetite, 59, 414-418.

Reeds, P. J., Burrin, D. G., Stoll, B., \& Jahoor, F. (2000). Intestinal glutamate metabolism. J. Nutrit., 130, 978S-982S.

Remy, E., Issanchou, S., Chabanet, C., \& Nicklaus, S. (2013). Repeated Exposure of Infants at Complementary Feeding to a Vegetable Puree Increases Acceptance as Effectively as Flavor-Flavor Learning and More Effectively Than Flavor-Nutrient Learning. Journal of Nutrition, 143, 1194-1200.

Schiffman, S. S. (2007). Critical illness and changes in sensory perception. Proceedings of the Nutrition Society, 66, 331-345.

Schiffman, S. S., \& Warwick, Z. S. (1993). Effect of flavor enhancement of foods for the elderly on nutritional status: Food intake, biochemical indices, and anthropometric measures. Physiology \& Behavior, 53, 395-402.

Schiffman, S. S., Zervakis, J., Westall, H. L., Graham, B. G., Metz, A., Bennett, J. L., \& Heald, A. E. (2000). Effect of antimicrobial and anti-inflammatory medications on the sense of taste. Physiology \& Behavior, 69, 413-424.

Sullivan, S. A., \& Birch, L. L. (1990). Pass the sugar, pass the salt: Experience dictates preference. Devel. Psychol., 26, 546-551.

Temple, J. L., Bulkley, A. M., Badawy, R. L., Krause, N., McCann, S., \& Epstein, L. H. (2009). Differential effects of daily snack food intake on the reinforcing value of food in obese and nonobese women. American Journal of Clinical Nutrition, 90, 304-313.

Winkler, S., Garg, A. K., Mekayarajjananonth, T., Bakaeen, L. G., \& Khan, E. (1999). Depressed Taste and Smell in Geriatric Patients J Am Dent Assoc, 130, 1759-1765.

Yeomans, M. R., Gould, N. J., Mobini, S., \& Prescott, J. (2008). Acquired flavor acceptance and intake facilitated by monosodium glutamate in humans. Physiology \& Behavior, 93, 958-966. 
507

508

509

510

511

512

513

514
Yeomans, M. R., Leitch, M., Gould, N. J., \& Mobini, S. (2008). Differential hedonic, sensory and behavioral changes associated with flavor-nutrient and flavor-flavor learning. Physiology \& Behavior, 93, 798-806.

Yeomans, M. R., Mobini, S., Elliman, T. D., Walker, H. C., \& Stevenson, R. J. (2006). Hedonic and sensory characteristics of odors conditioned by pairing with tastants in humans. J. Exp. Psychol.: Anim. Behav. Proc., 32, 215-228. 
Table 1: Design of the experiment (-MSG indicates no MSG added to soup, +MSG indicates $5 \%(w / w)$ MSG added to soup)

\begin{tabular}{|c|c|c|c|}
\hline GROUP & $\begin{array}{l}\text { SESSION } 1 \\
\text { Pre-conditioning session }\end{array}$ & $\begin{array}{l}\text { SESSIONS 2-7 } \\
\text { Conditioning sessions }\end{array}$ & $\begin{array}{l}\text { SESSION } 8 \\
\text { Post-conditioning session }\end{array}$ \\
\hline Group 1 & $\begin{array}{l}\text { Liking and preference for } \\
\text { Lemongrass AND Cumin } \\
\text { Group 1a: } \\
\text { consumption Lemongrass } \\
\text { Group 1b: consumption } \\
\text { Cumin }\end{array}$ & $\begin{array}{l}\text { This group consumed the } \\
\text { following soups on } \\
\text { alternate days: } \\
\text { Lemongrass +MSG, } \\
\text { Cumin -MSG }\end{array}$ & $\begin{array}{l}\text { Liking and preference for } \\
\text { Lemongrass AND Cumin } \\
\text { Group 1a: } \\
\text { consumption Lemongrass } \\
\text { Group 1b: consumption } \\
\text { Cumin }\end{array}$ \\
\hline Group 2 & $\begin{array}{l}\text { Liking and preference for } \\
\text { Lemongrass AND Cumin } \\
\text { Group } \mathbf{2 a} \text { : consumption } \\
\text { Lemongrass } \\
\text { Group } \mathbf{2 b} \text { : consumption } \\
\text { Cumin }\end{array}$ & $\begin{array}{l}\text { This group consumed the } \\
\text { following soups on } \\
\text { alternate days: } \\
\text { Lemongrass -MSG, } \\
\text { Cumin +MSG }\end{array}$ & $\begin{array}{l}\text { Liking and preference for } \\
\text { Lemongrass AND Cumin } \\
\text { Group 2a: consumption } \\
\text { Lemongrass } \\
\text { Group 2b: consumption } \\
\text { Cumin }\end{array}$ \\
\hline
\end{tabular}

Table 12: Questions and anchors used in session 1 and 8 using unstructured $100 \mathrm{~mm}$ line scales.

\begin{tabular}{ll}
\hline Question & Anchors \\
\hline Would you choose to have this particular soup? & No, not at all - Yes, very much \\
How much could you eat now of this soup? & None at all - A lot \\
How familiar are you with the flavour of this soup? & Not at all - Very familiar \\
How hungry are you now? & Not at all - Extremely \\
How strong is your desire to eat? & Very weak - Very strong \\
How good is your mood? & Unpleasant - Pleasant \\
Do you feel satiated (are you full)? & Not at all - Extremely \\
Could you eat more of this particular soup? & Not at all - Yes, definitely
\end{tabular}




\section{FIGURE CAPTIONS}

525 Figure 1: Mean (+/- standard error) change in liking of soup flavours from session 1 to 526 session 8 where participants had previously been exposed to the flavour with or without 527 MSG (MSG+, MSG- respectively)

528

529 Figure 2: Mean (+/- standard error) change in familiarity ratings between session 1 and 8 530 for cumin and lemongrass in those previously exposed to the flavour with or without MSG 531 (MSG+, MSG- respectively)

532

533 Figure 3: Mean (+/- standard error) ratings of hunger, desire to eat and mood, all

534 pre- consumption, at sessions 1 and 8 (Ratings from Questions 4, 5 and 6 in Table 12 ) 535

536 Figure 4: Mean (+/- standard error) consumption of soup in session 1 and session 8 where 537 participants were either exposed to the flavour with MSG (MSG+) or exposed to the flavour 538 without MSG (MSG-). 